\title{
Reports
}

\section{A Theory for El Niño and the Southern Oscillation}

Abstract. A coupled atmosphere-ocean model is presented for El Niño and the Southern Oscillation that reproduces its major features, including its recurrence at irregular intervals. The interannual El Niño-Southern Oscillation cycle is maintained by deterministic interactions in the tropical Pacific region. Ocean dynamics alter sea-surface temperature, changing the atmospheric heating; the resulting changes in surface wind alter the ocean dynamics. Annually varying mean conditions largely determine the spatial pattern and temporal evolution of El Niño events.

The oceanographic El Niño events (1) and the related atmospheric phenomena (2), known collectively as the Southern Oscillation, have been the subject of intense interest in recent years. The event of 1982/1983 was the largest in this century $(1,2)$ and had profound ecological, social, and economic consequences (3). Observed El Niño anomalies in the tropical Pacific Ocean have been explained as a response to changes in the surface wind stress (4). Briefly, westerly wind anomalies excite motions in the equatorial wave guide that depress the thermocline in the east, reduce equatorial upwelling, and enhance the eastward transport of warm surface waters from the western Pacific. All of these local and remote responses to the wind contribute to the rises in sea level and seasurface temperature (SST) that are characteristic of El Niño. Atmospheric models with specified SST anomalies have reproduced observed anomalies of the tropical atmospheric circulation $(2,5)$. How the coupled atmosphere-ocean system evolves through the El Niño-Southern Oscillation (ENSO) cycle is not well understood, however.

Both El Niño and the Southern Oscillation were known before the turn of the century, but it was not until the 1960's that the connection between the two was noted by Bjerknes (6). His explanation for the cycle was based on a positive feedback between ocean and atmosphere: stronger equatorial easterlies increase upwelling in the east and hence the east-west temperature contrast; this increases the thermal driving, thus creating stronger easterlies. The negative phase of this cycle is an El Niño event. With some modification (7), this central idea survives in all subsequent theories (8). None yet explains the recurrence of events on irregular intervals about every
3 or 4 years-that is, the ENSO cycle. We suggest such an explanation.

Our intent is to reproduce the salient features of the ENSO cycle with as simple a model as the essential physics will allow, not to simulate it precisely. We formulate a nonlinear model for the perturbations about a basic state derived from monthly mean climatologies of SST, surface winds, and thermocline depths (9). The dynamics of the atmospheric component of the model have been described (10). Although the physics of this simple one-mode linear response model can be justified only with great difficulty $(10,11)$, it gives surprisingly good results for the low-level tropi-

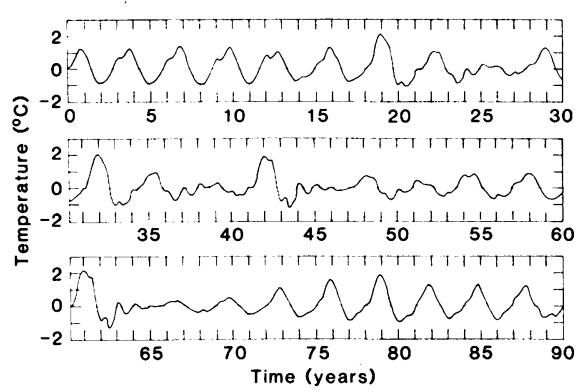

Fig. 1. The SST anomalies averaged over the eastern equatorial Pacific $\left(90^{\circ} \mathrm{W}\right.$ to $150^{\circ} \mathrm{W}, 5^{\circ} \mathrm{S}$ to $5^{\circ} \mathrm{N}$ ) for 90 years of model integration.
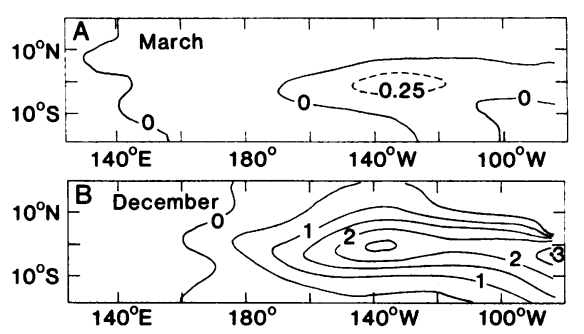

Fig. 2. March and December SST anomalies during the model El Niño event in year 31 . (Note that the contour interval for March is $0.25^{\circ} \mathrm{C}$ and that for December is $0.5^{\circ} \mathrm{C}$.) cal winds (11), especially when the heating is known (5). The heating in the model depends not only on mean and perturbation SST (10) but also on the mean and perturbation convergence (12, 13). The most important effect of the convergence feedback is to make the response sensitive to the pattern of divergence and convergence in the mean wind field. The seasonal migration of the Intertropical Convergence Zone (ITCZ) becomes especially important.

The ocean component of the model has also been described $(12,14)$; there was good agreement with observed SST anomalies during El Niño when forced by observed wind anomalies. The dynamics of the model are linear and quite simple. A time-dependent baroclinic upper ocean response is computed from a single layer reduced gravity model. The surface current is then found by adding an Ekman layer velocity to the baroclinic velocity.

The evolution equation for the perturbation SST is complete. It includes three-dimensional temperature advection by both the specified mean currents and the predicted anomalous currents. The temperature of upwelled water is specified as a function of thermocline depth. Since temperature changes more rapidly with depth when the thermocline is close to the surface, this function must be nonlinear. Because the mean thermocline is shallower in the east, the model is more sensitive there. The anomalous surface heating is taken to be linearly proportional to the temperature anomaly. This crude Newtonian cooling is consistent with our thesis that the SST anomalies essential to the ENSO cycle form in response to changes in the surface wind stress. We found the response to local forcing to be crucial, especially the changes associated with variations in the strength of equatorial upwelling. This result contrasts with others (15) and is a consequence of the inclusion in our model of the dynamics of the mixed layer (albeit in a simplified manner).

A numerical experiment with the coupled atmosphere-ocean model was initiated with an imposed $2 \mathrm{~m} / \mathrm{sec}$ westerly wind anomaly in the western Pacific for 4 months duration beginning in December of model year -1 . There was no external forcing thereafter. The model SST anomaly in the eastern equatorial Pacific for 90 years of model integration (Fig. 1) shows peaks of varying amplitude occurring at irregular intervals but typically 3 to 4 years apart. The peaks tend to be locked in phase with the annual cycle. Major events peak at the end of the calendar year and decay rapidly thereaf- 
ter. All of these features are characteristic of observed El Niño events (I). The amplitude of events is similar to observed ones, but the model spectrum is not as broad as the real one.

Figures 2 and 3 show the evolution of the El Niño event of year 31. In December of year 30 there is no discernible anomaly; by March (Fig. 2) there is a small but systematic anomaly in the eastern Pacific; by December (Fig. 2) the anomaly extends to the dateline, with a maximum at about $135^{\circ} \mathrm{W}$. The model patterns are fairly realistic [figures 1,3 , and 4 in (1)] except near the South American coast, where the model's coarse resolution prevents an accurate simulation of coastal upwelling processes.

The prominent feature in the evolution of anomalies in zonal wind along the equator is the band of westerlies in the central Pacific (Fig. 3). The spatial and temporal patterns are realistic until the year after the event, year 32. The westerly anomalies persist several months longer than is typical of actual El Niño events, and the model does not produce the characteristic easterly anomalies in the far western Pacific [figure 4 in (I)]. In general, model SST anomalies persist longer than is the case in typical El Niño events. As with observed events, the positive SST anomalies disappear rapidly, leading to negative SST and easterly wind anomalies.

Results from the ENSO model suggest the following hypotheses: The actual ENSO cycle is an oscillation of the coupled atmosphere-ocean system. The interactions essential to creating and maintaining the cycle all take place in the tropical Pacific region. No extratropical influences need to be invoked to account for either the initiation or termination of ENSO events. That the surface layer of the ocean can respond strongly and swiftly to atmospheric changes influences the character of El Niño events profoundly, but the basinwide response of the upper ocean down to the thermocline is necessary for the interannual variability that defines the phenomenon.

Warm events result from a positive feedback between anomalies in the atmosphere and the ocean. Warmer than normal SST in the east leads to increased atmospheric heating. The anomalous inflow into this heating region includes westerly surface winds along the equator in the central Pacific. The associated change in surface wind stress reduces upwelling, drives an eastward current, and deepens the thermocline in the east. These responses reinforce the warm SST anomaly. This positive feedback is es- sentially the same mechanism proposed by Bjerknes, the most significant change being the inclusion of nonlocal modes of oceanic response. However, the feedback will not take hold unless a necessary condition for the instability of the coupled system is satisfied. Model results suggest that El Niño events will not develop if the zonally integrated heat content in the equatorial Pacific wave guide is lower than its average value (16).

If conditions are favorable, an event may be triggered by a variety of perturbations, the most readily available being the bursts of westerly wind that occur with great frequency in the western equatorial Pacific (17). Mean conditions in the (northern) summer and fall are favorable to the positive feedback.

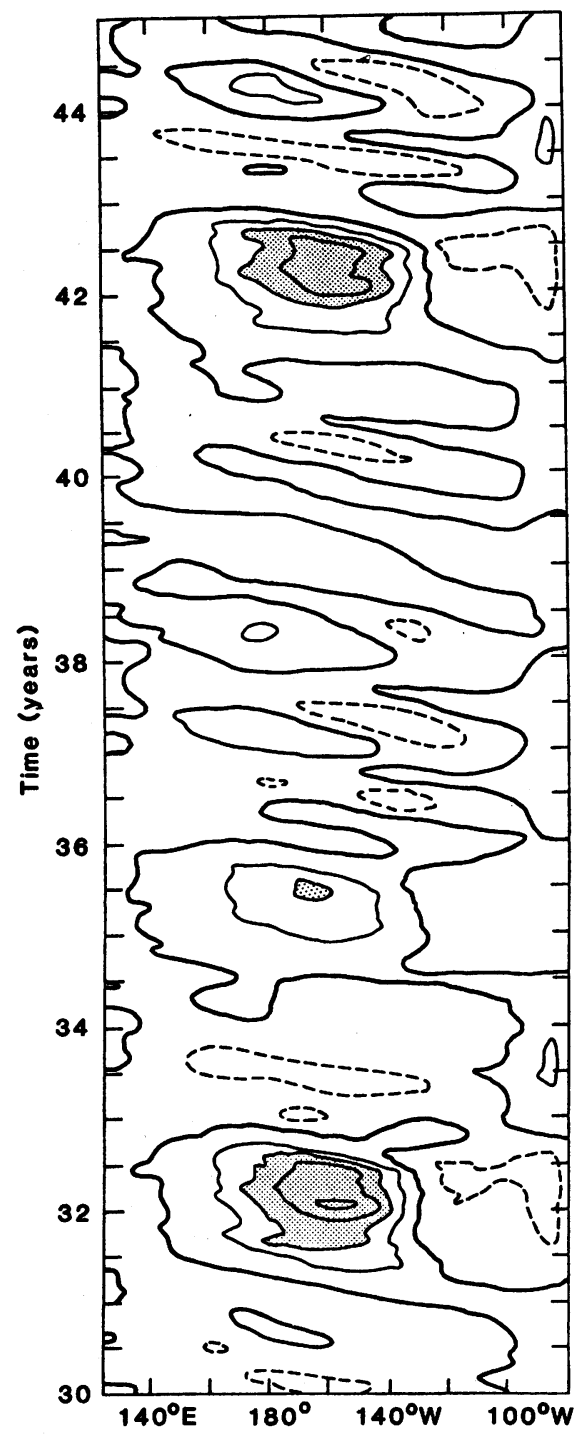

Fig. 3. Time-longitude sections of the forcing for the gravest mode oceanic Kelvin wave, a measure of zonal wind anomalies along the equator [figure 4 in $(I)$ ]. The 0 contour is the heavy solid line, positive contours are solid lines, negative contours are dashed lines, and the interval is approximately $0.7 \mathrm{~m} / \mathrm{sec}$.
Hence, once begun, ENSO anomalies will grow to large amplitude during those seasons. In the following spring the normal seasonal changes in mean conditions (reductions in trade winds, upwelling, and zonal temperature gradient) weaken the coupling between atmospheric and oceanic anomalies and the warm event can no longer be sustained (18). As the system relaxes, it overshoots the mean state in a manner characteristic of equatorial ocean dynamics, producing the cold SST's and stronger than normal easterlies typical of the year following an El Niño event. At this time the heat content of the equatorial ocean is lower than normal. During the next few years the equatorial heat reservoir is refilled until the ocean is once again prepared to sustain a warm event (19).

In both the model and in nature, ENSO is clearly aperiodic. Since the model system is deterministic, the aperiodicity there results from deterministic interactions, not random fluctuations of unknown origin. This is an encouraging prospect for predicting El Niño events, although there are theoretical limits to the predictability of deterministic, nonlinear systems exhibiting such chaotic behavior. The model is simpler than the set of interactions that account for real ENSO events, so it is unlikely that the real events are more predictable than the model ones.

Mark A. Cane STEPHEN E. Zebiak

Lamont-Doherty Geological Observatory, Palisades, New York 10964

\section{References and Notes}

1. M. A. Cane, Science 222, 1189 (1983).

2. E. M. Rasmusson and J. M. Wallace, ibid., p. 1195 .

3. R. T. Barber and F. P. Chavez, ibid., p. 1203; T. Y. Canby, Natl. Geogr. 165, 144 (1984).

4. The essential physical mechanisms are described more fully in (I); also see J. P. McCreary, Annu. Rev. Fluid Mech. 17, 359 (1985).

5. A. E. Gill and E. M. Rasmusson, Nature (London) 306, 229 (1983).

6. J. Bjerknes, Tellus 18, 820 (1966); Mon. Weather Rev. 97, 163 (1969); J. Phys. Oceanogr. 2, 212 (1972).

7. P. R. Julian and R. M. Chervin, Mon. Weather Rev. 106, 813 (1978)

8. K. Wyrtki, Mar. Tech. Soc. J. 16, 3 (1982); J. C. McWilliams and P. R. Gent, J. Atmos. Sci. 35, 962 (1978); J. P. McCreary, Mon. Weather Rev. 111, 370 (1983); S. G. H. Philander, Nature (London) 302, 295 (1983).

9. Winds and SST obtained from the Climate Analysis Center, NOAA; subsurface data from C. Colin et al [Cah. ORSTOM Ser. Oceanogr. 7, 167 (1971)].

10. S. E. Zebiak, J. Atmos. Sci. 39, 2017 (1982).

11. J. E. Geisler and D. E. Stevens, Q. J. R. Meteorol. Soc. 108, 87 (1982).

12. S. E. Zebiak, thesis, Massachusetts Institute of Technology, Cambridge (1984).

13. P. Webster, J. Atmos. Sci. 38, 554 (1981).

14. S. E. Zebiak and M. A. Cane in "Papers from the 1982-83 ENSO data display workshop" (Atlantic Oceanographic and Meteorologica Laboratories, Miami, 1983).

15. A. E. Gill, J. Phys. Oceanogr. 13, 586 (1983); D. E. Harrison and P. S. Schopf, ibid. 14, 923 (1984). 
16. The stated condition appears to be consistent with the sketchy observational data that is available. We expect that the precise necessary condition is more subtle, even within the model.

17. D. S. Luther, D. E. Harrison, R. A. Knox Science 222, 327 (1983). The model does not produce these westerly bursts; more generally, it understates the variability of the atmosphere over the western Pacific. However, the model does exhibit high-frequency variability in the central Pacific, which can have the same triggering effect.

18. A calculation without the mean annual cycle (perpetual May condition) also gives long-period oscillations, but its evolution and amplitude decays in a completely different way than rea events and the full model.

19. Ocean dynamics determine a tendency toward a positive heat anomaly along the equator in repositive heat anomaly along the equator in response to equatorially confined easterly wind
anomalies. [See M. A. Cane and E. S. Sarachik, anomalies. [See M. A. Cane and E. S. Sarachi
J. Mar. Res. 39, 651 (1981), figures 2 and 3.]

20. Supported by NASA grants NAGW 463 and NAGW-582 and grant OCE 84-44718 from the National Science Foundation. Contribution 3803 of the Lamont-Doherty Geological Observatory.

27 December 1984; accepted 14 March 1985

\section{The Diversification of the Leguminosae: First Fossil}

\section{Evidence of the Mimosoideae and Papilionoideae}

\begin{abstract}
The legumes are an important group of flowering plants with a poorly documented evolutionary history. New fossil evidence provides data on the timing of the origin of the two derived subfamilies of legumes (the Mimosoideae and Papilionoideae). These data strongly suggest the importance of bee pollinators during a major period of angiosperm diversification.
\end{abstract}

The legume family of flowering plants is large (14,000 species) and economically and ecologically important. Because the fossil record has not provided enough information to allow an assessment of their putative evolutionary history, it has been necessary to reconstruct their evolutionary history from contemporary biogeography or to infer it from the comparative morphology of modern taxa $(1,2)$. The legumes are generally thought to have originated during the Upper Cretaceous in west Gondwanaland and to have subsequently diversified into three subfamilies, Mimosoideae, Caesalpinioideae, and Papilionoideae, which were well defined by the Middle Eocene $(1,2)$. Evolution within the legumes is regarded as having proceeded from taxa with generally open flowers and vulnerable nectar and pollen, mostly in the subfamily Caesalpinioideae, toward taxa with flowers modified to protect these resources, the Mimosoideae and Papilionoideae, in conjunction with increasing pollinator specificity, in particular the bee pollinators that are fundamental to the family today (3).

The fossil record of the legumes is tantalizing; leaflets and fruits are fairly well known from the Middle Eocene on, but the reports are rarely accompanied by data that support the suggested affinities. As interpreted on the basis of unequivocal fossil evidence (2), the history of the legumes begins with Upper Cretaceous pollen of the Caesalpinioideae. The Mimosoideae appeared by the Middle Eocene on the basis of pollen and varied megafossil evidence (2), and the Papilionoideae with highly derived zygomorphic flowers have no fossil record until the appearance of Pliocene pollen (4). New fossil floral evidence, discovered at a single locality in western Tennessee, reveals that the two derived subfamilies, the Mimosoideae and Papilionoideae, were well developed by the Paleocene-Eocene boundary.

The fossil mimosoid inflorescences are racemose. Floral envelopes consist of a deeply lobed calyx and five valvate petals. There are ten stamens of uneven length with versatile, sagittate anthers (Fig. 1a). Pollen is shed in monads of tricolporate grains, and exine is smooth perforate with tectate-columellate ultrastructure (Fig. 1, d through $\mathrm{f}$ ). The pollen wall is distinctive because the columellae are relatively long (Fig. 1e). Ovaries are superior and stipitate and are sometimes preserved in an expanding condition (Fig. 1a). The stigmatic region is occasionally well preserved. Stigmas are tubular (a mimosoid character) and tiny $(0.10 \mathrm{~mm}$ in diameter). In one fossil the stigma is packed with the same type of pollen that has been isolated from its anthers and those of similar specimens (Fig. 1, $c$ and d). The presence of pollen in the stigma of this flower is consistent with the expanding ovary and suggests that it had been fertilized as well as pollinated at the time of preservation. The extremely small size of the stigma and the fact that it was filled with one kind of pollen are evidence consistent with insect pollination.

We verified the affinities of these fossil flowers by entering 23 discernible characters into an open access key (5) and then by considering pollen micromorphology, ultrastructure, stigma type, and ovary position. Only the subfamily Mimosoideae of the Leguminosae circum- scribes all these characters. The fossils do not, however, share their entire complement of characters with the flowers of any single modern genus and represent an extinct taxon.

Character state polarities in the Mimosoideae were recently suggested on the assumption that the Dimorphandra group of the subfamily Caesalpiniodeae, tribe Caesalpineae, are the closest related nonmimosoid legumes (6). By this standard, most of the characters of these fossil flowers are primitive in the subfamily [that is, the morphocline and chronocline are congruent (7)]. Moreover, the fossils are consistent with the possibility that mimosoid ancestors were Dimorphandra-like because they share several characters with the taxa composing that subfamily $(8)$. One of these characters, pollen micromorphology, appears to be a synapomorphy linking the Mimosoideae and the Dimorphandra group of the Caesalpinieae (Fig. 1f) (8).

Unequivocal evidence of the most derived of legume subfamilies, the Papilionoideae, is missing from the pre-Pliocene fossil record (4), but papilionoid flowers have been discovered in Paleocene-Eocene sediments (Fig. 1, b and g). Flowers are often preserved with an expanding ovary (Fig. 1b). Floral and fruit characters limit the affinities to the legumes (5), and floral envelope features are typical of the papilionoid legumes in particular. The calyx is unevenly lobed, and the corolla consists of a standard, two wing petals, and a partially fused keel (Fig. 1, b and g). In the Leguminosae, zygomorphic flowers are not restricted to the Papilionoideae. Although uncommon, they are also found in the subfamily Caesalpinioideae. Two floral envelope characters differentiate flowers of the two subfamilies. First, there is a significant difference in aestivation. In the true papilionoid flower the standard is inserted outside the wing petals, whereas in the caesalpinioids the wing petals include the standard (9). In the fossils it has been possible to determine the relative positions of the standard and wing petals, because in one specimen floral envelope preservation is three-dimensional and illustrates that the base of the standard is outside the wing petals.

Another floral envelope feature that separates the papilionaceous caesalpinioids from the true Papilionoideae is wing petal sculpturing (10). Wing petals serve three functions in the papilionoid legumes: they are attractants, they provide a landing platform, and they serve as levers to move the wing-keel complex downward to facilitate pollination and 